Doi: HTTPS://DOI.ORG/10.23910/IJBSM/2018.9.1.3C0137b

\title{
Response of Myrtus communis Seedlings under Irrigation Frequencies
}

\author{
Valasia lakovoglou* and Evmorfili Kokkinou
}

Department of Forestry and Natural Environment Management, Mediterranean Eastern Macedonia and Thrace Institute of Technology - 1st km. Dramas Michrohoriou Drama, Drama (66 100), Greece

\author{
Corresponding Author \\ Valasia lakovoglou \\ e-mail: viakovoglou@yahoo.com
}

\author{
Article History \\ Article ID: 3C0137b \\ Received in $14^{\text {th }}$ September, 2017 \\ Received in revised form $25^{\text {th }}$ October, 2017 \\ Accepted in final form $19^{\text {th }}$ December, 2017
}

\begin{abstract}
Nowadays the impacts of climate change are more abrupt. Semi arid Mediterranean ecosystems like Greece are characterized by frequent and intense drought events that, in conjunction with reduced water availability particularly during summer, pose obstacles to restoration efforts. The aim of this study was to investigate the growth of Myrtus communis L. seedlings under three irrigation frequencies: watering once every two weeks, once every week and three times every week for the experimental period of two months. A number of morphological variables were evaluated in addition to root growth potential and the seedlings' dry weights for the first and the second month of the experiment. According to the results, the species was able to maintain its normal growth condition for a period of one month, even under the least irrigation frequency of one watering every two weeks. However, by the end of the second month of growth the negative impact of reduced irrigation was evident with three times watering every week having better seedling responses. Specifically, those seedlings had greater root growth potential; a characteristic that relates with increased transplanting success. Therefore, based on the results of the study, the species of Myrtus Communis can cope with adverse drought growth conditions as reflected by low irrigation frequency (one watering every two weeks) for a period of one month. Nonetheless, by the end the second experimental month, watering three times every week resulted in better growth responses while the species indicated avoidance mechanisms (e.g. leaf abscission) that enabled the species to cope with drought conditions.
\end{abstract}

Keywords: Climate change, ecophysiology, reforestation, transplanting success, water stress

\section{Introduction}

Nowadays the impacts of climate change are more abrupt. Some areas experience intense rain fall events while others droughts. Semi arid Mediterranean ecosystems like Greece are characterized by frequent and intense drought events that according to the predicted climatic alterations their severity and duration will increase (Xoplaki et al., 2005; Lionello et al., 2006; IPCC, 2013). Researchers worry that climate change will not only pose obstacles to the growth of the species (Olivar et al., 2015), but will also test their ability to cope with those abrupt climatic alterations and eventually threat their existence (Gritti et al., 2006).

Mediterranean areas retain highly valuable ecosystems of particular ecological significance since they are characterized by high biodiversity levels. However, the prevailing semi-arid climate that nowadays has been associated with intense drought events due to climatic change, induce restoration problems (Mitrakos 1980, Villar-Salvador et al., 1999, Scarascia-Mugnozza et al 2000, Rudel 2007). Consequently, the most important factor that affects negatively the survival and growth of plants is drought, particularly during the summer (Salvador et al., 1999). The response of each plant species to water availability is associated with avoidance and tolerance mechanisms that are related to morphological and physiological characteristics. Of particular interest is the ability of a species to grow well-developed root systems with increased potential of newly developed roots (Carlson and Miller, 1990; Villar-Salvador et al., 2008). These characteristics could be very good indicators of the species ability to avoid or tolerate water deficit conditions that is also associated with the ability of the species to withstand transplanting stress and survive (Keeley 1998, Sircelj et al., 2007; Ackerly, 2004, Lambers et al., 2006).

One of the highly valuable Mediterranean species is Myrtus communis L. (common myrtle) due to its aromatic and therapeutic abilities from extracts derived from the leaves, stem and seeds of the plant. It is a perennial evergreen shrub and belongs to the Myrtaceae family (Athanasiadis 1986, Sumbul et al., 2011, Rahimmaleka et al., 2013). It is considered native in the Southern European Mediterranean climates like Greece (Touaibia, 2015), while it grows in 
Northern Africa and Western Asia (Zilkah and Goldschdmidt 2014, Athanasiadis, 1986). The main objective of this study was to investigate the effect of irrigation frequencies on the growth of Myrtus communis. It was hypothesized that as water frequency decreased the ability of the plant to grow and develop new root systems would also decrease indicating a tolerance mechanism of the species to withstand water deficit conditions. The results of this study will help address the ability of the species to maintain growth under reduced irrigation frequencies. Eventually, the best growth response could be achieved under an irrigation frequency that will also same water, something that is of vital importance due to lack of water availability particularly during summer months.

\section{Materials and Methods}

\subsection{Experiment conditions}

The experiment was carried out in Amisiana area of Kavala during autumn of 2013. In order to fully control the irrigation frequency of the seedlings from unexpected rainfall events, the experiment took place under outdoor shed conditions. Prior to the experiment, the seedlings were grown for three years under greenhouse conditions of daily irrigation and weekly fertilization in $55 \times 60 \times 160 \mathrm{~cm}^{3}$ containers (soil mixture of 1-to-3 perlite and peat, respectively).

In order to assess the root growth potential (RGP) of the three year old Myrtus communis seedlings, the seedlings were transplanted into larger containers of $110 \times 120 \times 320$ with similar 1-to-3 perlite and peat mixture. Three were the studied irrigation frequencies: watering once every two weeks, watering once every week and watering three times every week for the total experimental period of two months. Each month, six randomly picked seedlings were harvested and evaluated for each irrigation treatment.

\subsection{Studied variables}

Each experimental month, the seedlings were extracted from the containers and were carefully washed to remove the excess soil from the roots. The studied variables were the Height, the Root Collar (RC), the Maximum Root Length (MRL), the Number of Leaves (NL) and the Number of Lateral Roots (NLR). The dry weights of the seedlings were also evaluated through the help of an electronic scale (four digits accuracy) after placing them in a conventional oven for 24 hours at $80^{\circ}$ C (Wilson et al., 1999). The above ground estimated seedling dry weight variables were the Leaf Dry Weight (LDW), the Stem Dry Weight (SDW) and the Upper seeding Dry Weight (UPDW). The bellow ground estimated variables of the dry weight of the seedlings were the Tap Root Dry Weight (TRDW), the Lateral Root Dry Weight (LRDW) and the Down Part Dry Weight (DNDW). In addition, the Total Seedling Dry Weight (TSDW), the Root/Shoot Ratio (RATIO) and the dry weight of the Root Growth Potential (RGP) were also estimated.

The statistical analysis of the data was conducted by using the ANOVA analysis with the SPSS ${ }^{\circledR}$ statistical software v.
15.0 [SPSS. 2006] with the data been tested for normality and homogeneity. The mean differences were tested with the Duncan's multiple range tests at significance levels of $p<0.01$.

\section{Results and Discussion}

According to the experimental results there was a substantial effect of the irrigation treatments on the characteristics of the Myrtus cummunis seedlings, with the second experimental month having a more profound effect (Figure 1 and Figure 2). Specifically for the first month, from the seedling characteristics of height, NL, RC, NLR, MRL and RATIO (Figure $1)$, only the variable of the NL differed among irrigation treatments, with the three watering per week having a greater mean. This indicates that for the species of Myrtus cummunis, the number of leaves is an easily measurable variable that indicates alterations in the response of the species when experiencing water deficit conditions such as watering once every week.

Based on these results it is evident that the effect of treatments was more profound during the second month of the experiment (Figure 1). Specifically for the second experimental month, the height, the NL, the NLR and the MRL were greater for seedlings when watered three times or once a week compared to the most conservative irrigation treatment of once every two weeks. This shows that for the period of one month, the species of Myrtus communis, was able to cope and maintain its growth under reduced water supplies even for an irrigation frequency of one watering every two weeks and maintain its physiological condition. However, after the period of one month the results indicated that the plants were facing difficulties in coping the adverse watering growth conditions, particularly when watering once every two weeks. Therefore, the two-month interval was necessary to detect the effect of irrigation frequency on the studied variables. Only the RATIO had the highest mean value for the treatment of one watering every two weeks. Consequently, by reducing the frequency of water supply there has been a shift in the carbon allocation towards the root biomass of the plants, which is consistent with the cited literature (lakovoglou and Halivoloulos, 2016).

It worth's mentioning that seedlings showed an increased ability to produce longer new root system (MRL) under the irrigation frequency of three watering per week (Figure 1). The same growth pattern was observed for the biomass accumulation based on the dry weights of the RGP (Figure 2). Based on other studies it has been indicated for the species of Pinus halepensis that for the experimental duration of one month, watering once every two weeks resulted in better root growth potential (Syropli et al., 2015). The results might differ from this study due to alterations based on species responses (Myrtus communis vs Pinus halepensis). Consequently, the species-effect should never be neglected, since it highly affects the experimental results.

Based on the results of the mean dry weights of the seedlings 

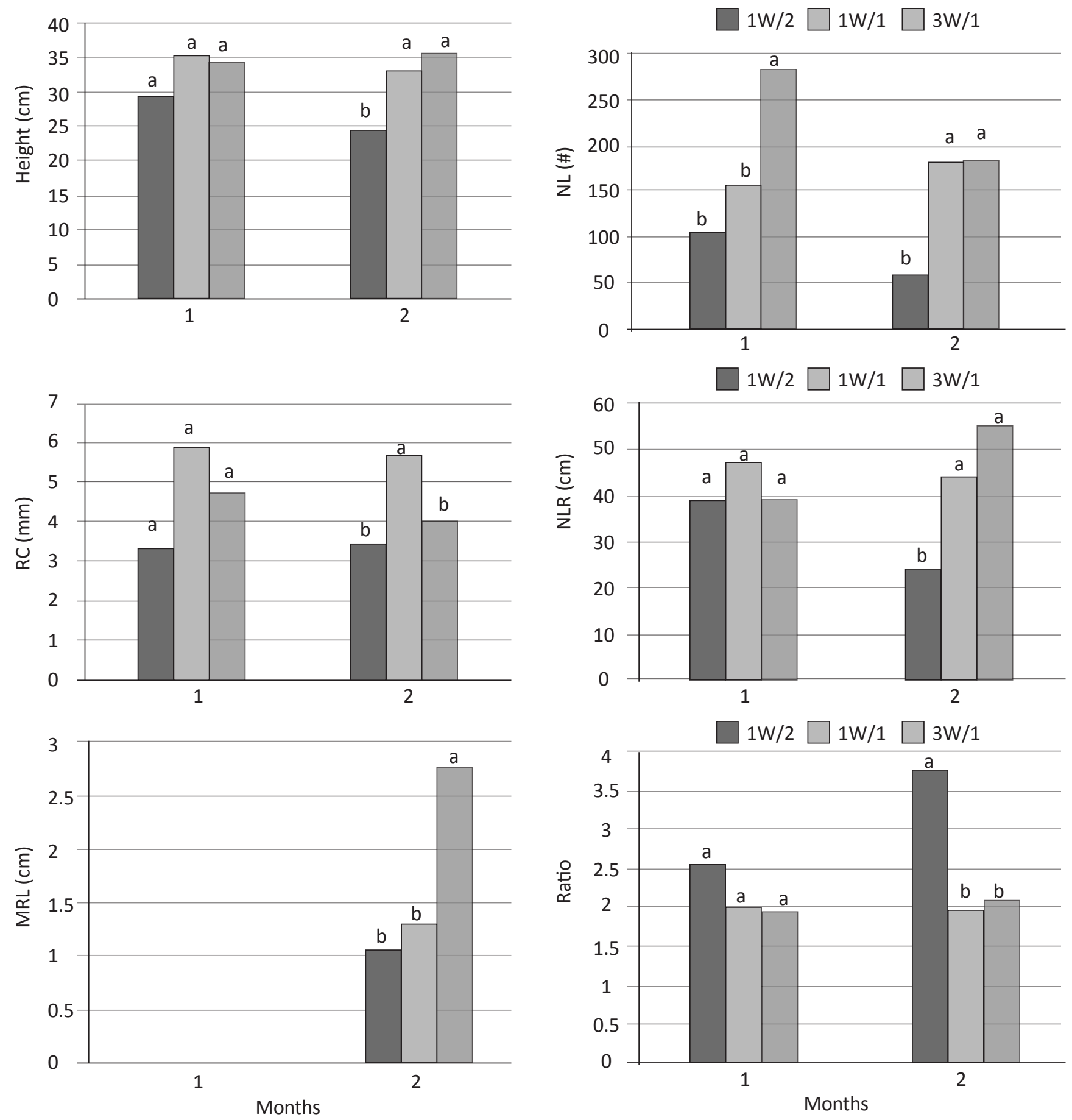

Figure 1: Differences among irrigation treatments (significance at $p<0.01$ ) of Myrtus communis for the first (1) and second (2) experimental month for the studied variables of: Height (HGT); Root collar (RC), the Maximum root length (MRL); No. of leaves (NL); No. of lateral roots (NLR) and root/shoot ratio (RATIO).

for the second experimental month, the mean dry weights of the seedlings reduced when compared to the first month of growth (Figure 2). This might indicate an avoidance mechanism of the species to withstand the drought conditions that were associated with abscission of leaf and root biomass. Consequently, the seedlings lost part of their leaves in order to alleviate stress related to the increased transpiration demand under conditions of reduced water availability. Further, based on the results, significant differences were noted for the TRDW and DNDW with greater mean values for the seedlings that were watered three times and once every week, while the RGP was greater for seedlings that were watered three times 

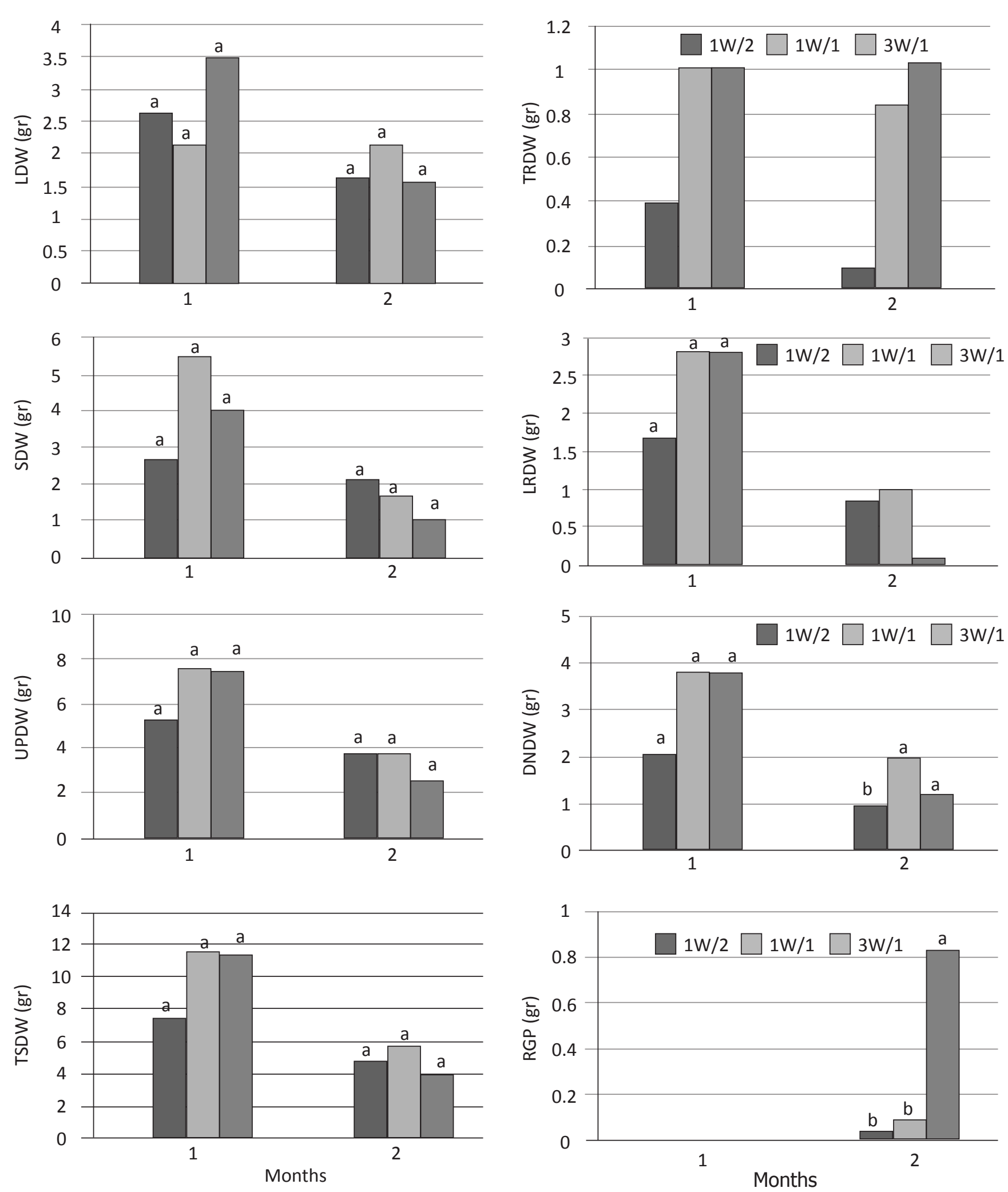

Figure 2: Differences among irrigation treatments (significance at $p<0.01$ ) of Myrtus communis for the first (1) and second (2) experimental month for the above ground seedling dry weight variables of: Leaf dry weight (LDW); Stem dry weight (SDW); Upper seeding dry weight (UPDW); Total seedling dry weight (TSDW) and the bellow ground seedling dry weight variables of: Tap Root Dry Weight (TRDW); Lateral Root dry weight (LRDW); Down part dry weight (DNDW) and the dry weight of the root growth potential (RGP) 
a week. In contrast, the LRDW was greater for the seedlings that were watered once every week and every two weeks. This indicates that although the species of Myrtus communis is considered drought tolerant, it can withstand water stress for at least one month without a noticeable negative effect on its physiological status. However, after that timeframe, the seedlings in order to maintain their normal growth they needed at least one watering per week. Further, for this species, the three watering per week were ideal for the normal growth of plants for the duration of two months, with increased ability to grow new roots; a characteristic that will allow the species to further explore nutrients and water to maintain its physiological status.

\section{Conclusion}

Myrtus communis was able to withstand unfavorable irrigation frequency of one watering every two weeks for the period of one month. However, by the second month, watering once every week and every two weeks led to negative growth effects. Therefore, three watering every week for the period of two months were adequate to maintain the growth and the ability of the seedlings to develop new root systems; an important characteristic for their survival.

\section{References}

Ackerly, D., 2004. Functional strategies of chaparral shrubs in relation to seasonal water deficit and disturbance. Ecol Monogr 74, 25-44.

Athanasiadis, N., 1986. Forest botany II. Trees and shrubs of the Greek forests (in Greek). Giahoudis-Giapoulis, Greece.

Carlson, W.C., Miller, D.E., 1990. Target seedling root system sizehydraulic conductivity, and water use during seedling establishment. In: Rose, R., Campbell, S.J., Landis T.D. (Ed.), Proceedings, Combined Meeting of the Western Forest Nursery Association's Target Seedling Symposium. Gen. Tech. Rep. RM-200. Fort Collins, CO. USDA Forest ServiceRocky Mtn. For. and Range Exp. Stn., 79-90.

Gritti, E.S., Smith, B., Sykes, M.T., 2006. Vulnerability of Mediterranean Basin ecosystems to climate change and invasion by exotic plant species. Journal of Biogeography 33, 145-157.

lakovoglou, V., Halivopoulos, G., 2016. Ecophysiology responses of preconditioning of forest species. A Review. Journal of Engineering Science and Technology Review 9(1), 7-11.

IPCC, 2013. Climate change 2013. The physical science basis. Intergovernmental panel on climate change, Cambridge University Press, Cambridge, UK.

Keeley, J.E., 1998. Coupling demography, physiology and evolution in chaparral shrubs. In: Rundel, P.W., Montenegro, G., Jaksic, F.M. (Ed.), Landscape disturbance and biodiversity in Mediterranean-type ecosystems. Springer-Verlag, New York, 257-264.
Lamber, H., Shane, M.W., Cramer, M.D., Pearse, S.J., Veneklaas, E.J., 2006. Root structure and functioning for efficient acquisition of phosphorus: Matching morphological and physiological traits. Ann Bot. 98, 693-713.

Lionello, P., Malanotte- Rizzoli, Boscolo, R., Alpert, P., Artale, V., Li, L., Luterbacher, J., May, W., Trigo, R., Tsimplis, M., Ulbrich, U., Xoplaki, E., 2006. The Mediterranean Climate: An Overview of the Main Characteristics and Issues. Developments in Earth and Environmental Sciences 4, 1-26.

Olivar, J., Bogino, S., Spiecker, H., Bravo, F., 2015. Changes in climate-growth relationships and IADF formation over time of pine species (Pinus halepensis, $P$. pinaster and $P$. sylvestris) in Mediterranean environments. Forest Systems 24(1), 1-9.

Mattsson, A., 1986. Seasonal variation in root growth capacity during cultivation of container grown Pinus sylvestris seedlings. Scandinavian Journal of Forest Research 1, 473-482.

Mitrakos, K., 1980. A theory for Mediterranean plant life. Oecolog Plantar 15, 245-252.

Rahimmaleka, M., Mirzakhanib, M., Pirbaloutiba, A.G., 2013. Essential oil variation among 21 wild myrtle (Myrtus communis L.) populations collected from different geographical regions in Iran. Industrial Crops and Products 51, 328-333.

Rudel, P.W., 2007. Mediterranean climate ecosystems. Encyclopedia of biodiversity 3, 1-15.

Salvador, P.V., Ocana, L., Penuelas, J., Carrasco, I., 1999. Effect of water stress conditioning on the water relations, root growth capacity, and the nitrogen and non-structural carbohydrate concentration of Pinus halepensis Mill. (Aleppo pine) seedlings. Annals of Forest Science 56, 459-465.

Scarascia-Mugnozza, G., Oswald, H., Piussic, P., Radoglou, K., 2000. Forests of the Mediterranean region: gaps in knowledge and research needs. Forest Ecology and management 132, 97-109.

Sircelj, H., Tausz, M., Grill, D., Batic, F., 2007. Detecting Different Levels of Drought Stress in Apple Trees (Malus domestica Borkh.) with Selected Biochemical and Physiological Parameters. Scientia Hort. 113, 362-369.

SPSS, 2006. Rel. 15.0, Chicago, SPSS.

Sumbul, S., Ahmad, M.A., Asif, M., Akhtar, M., 2011. Myrtus communis Linn. $3 / 4$ A review. Indian Journal of Natural Products and Resources 2(4), 395-402.

Syropli, Aik., lakovoglou, V., Radoglou, K., 2015. Pinus brutia and its response under different irrigation frequencies. In: International Conference: Frontiers in Environmental and Water Management, March 19-21, 2015, Kavala, Greece, 161-165.

Touaibia, M., 2015. Antimicrobial activity of the Essential oil of Myrtus communis L. berries growing wild in Algeria. Journal of Fundamental and Applied Science 7(2), 150-162. 
Villar-Salvador, P., Ocana, L., Penuelas, J., Carrasco, L., 1999. Effect of water stress conditioning on

the water relations, root growth capacity, and the nitrogen and non-structural carbohydrate concentration of Pinus halepensis Mill. (Aleppo pine) seedlings. Annals of Forest Science 56, 459-465.

Villar-Salvador, P., Valladeres, F., Dominguez-Lerena, S., Ruiz-Diez, B., Fernandez-Pascual, M., Delgado, A., Penuelas, J.L., 2008. Functional traits related to seedling performance in the Mediterranean leguminous shrub Retamasphaerocarpa: Insights from a provenance, fertilization, and rhizobial inoculation study.
Environmental and Experimental Botany 64, 145-154.

Zilkah, S., Goldschdmidt, E.E., 2014. Myrtle (Myrtus communis L.) - A Native Mediterranean and Cultured Crop Species. Medical and aromatic plants of the world 2, 253-267.

Xoplaki, E., Luterbacher, J., Paeth, H., Dietrich, D., Steiner, N., Grosjean, M., Wanner, H., 2005. European spring and autumn temperature variability and change of extremes over the last half millennium. Geophysical Research Letters 32, 1-4. 